\title{
Glyphosate residues alter the microbiota of a perennial weed with a minimal indirect impact on plant performance
}

\author{
S. Ramula (D) S. A. Mathew (D) A. Kalske (D). \\ R. Nissinen (D) K. Saikkonen (D) M. Helander
}

Received: 5 March 2021 / Accepted: 19 October 2021 / Published online: 6 November 2021

(C) The Author(s) 2021, corrected publication 2022

\begin{abstract}
Purpose In cold climates, glyphosate residues may linger in soils, with effects on plant-microbe interactions and, consequently, plant performance. Here, we explore the influence of glyphosate residues on the endophytic microbiota (bacteria and fungi) and performance of the perennial nitrogen-fixing weed Lupinus polyphyllus.

Methods In a common garden, we grew plants from six populations of L. polyphyllus in glyphosatetreated or untreated control soils, with or without additional phosphorus. We sampled plant microbiota (leaves, roots, nodules) and assessed plant performance based on six traits: height, retrogression
\end{abstract}

Responsible Editor: Luz E. de-Bashan.

Supplementary Information The online version contains supplementary material available at https://doi. org/10.1007/s11104-021-05196-1.

S. Ramula $(\varangle) \cdot$ S. A. Mathew · A. Kalske $\cdot$ M. Helander Department of Biology, University of Turku, 20014 Turku, Finland

e-mail: satu.ramula@utu.fi

S. A. Mathew $\cdot$ K. Saikkonen

Biodiversity Unit, University of Turku, 20014 Turku, Finland

R. Nissinen

Department of Biological and Environmental Science, University of Jyväskylä, P.O. Box 35, 40014 Jyväskylä, Finland probability (i.e. shrinkage), biomass, root:shoot ratio, nodule number, and nodule viability.

Results The richness of plant endophytic microbial communities was determined by soil phosphorus level rather than by glyphosate treatment. However, for bacteria, the composition of these communities differed between glyphosate-treated and control soils across plant tissue types; no difference was observed for fungi. The plant bacterial communities in both soil types were dominated by potential nitrogen-fixing bacteria belonging to family Bradyrhizobiaceae, and particularly so in glyphosate-treated soils. Overall, though, these changes in plant bacterial communities had a minor effect on plant performance: the only difference we detected was that the probability of retrogression was occasionally higher in glyphosate-treated soils than in control soils.

Conclusion Our findings indicate that glyphosatebased herbicides, when applied at the recommended frequency and concentration, may not have critical effects on the growth of short-lived weeds after the safety period has passed; however, the endophytic microbiota of such weeds may experience longer-lasting shifts in community structure.

Keywords Glyphosate $\cdot$ Herbicide $\cdot$ Microbiota . Plant traits $\cdot$ Rhizobia $\cdot$ Roundup 


\section{Introduction}

Glyphosate-based herbicides are the most common and efficient method of control for weeds (reviewed in Kettenring and Reinhardt Adams 2011). Glyphosate is lethal for practically all plant species (Duke and Powles 2008) because it affects the shikimate synthesis pathway, thus preventing plant growth (Helander et al. 2012). The efficient translocation of this chemical in plant tissues and its presumed immobility in soils make glyphosate preferable to many other herbicides (Duke and Powles 2008). Moreover, it has been claimed that glyphosate degrades in soils within a few weeks, with a minimal impact on non-target organisms (Baylis 2000; Duke and Powles 2008). However, previous studies have suggested that glyphosate may linger in northern soils after the safety period has passed (Laitinen et al. 2009; Helander et al. 2012, 2018). Moreover, glyphosate residues are found in both target (weed) and non-target (crop) species several months after application (Helander et al. 2018), with detectable effects on herbivores (Gómez-Gallego et al. 2020). This herbicide may thus affect a suite of organisms for a longer period of time than expected.

Even at recommended concentrations of herbicides, glyphosate can reduce the number and activity of soil microbes (Angelini et al. 2013; Helander et al. 2018), many of which possess a shikimate synthesis pathway similar to that of plants (Helander et al. 2012; Leino et al. 2021; Rainio et al. 2021). As a consequence, plants that rely on mutualistic relationships with soil micro-organisms may be indirectly affected by glyphosate residues through quantitative and/or qualitative changes in soil microbiota (e.g., Helander et al. 2012; Fuchs et al. 2021). Such effects, in turn, may result in shifts in the composition of plant microbiota-the bacterial and fungal micro-organisms associated with plant tissues both belowground and aboveground-which can be essential for plant growth and stress tolerance (reviewed in Compant et al. 2019).

Beyond the safety period, glyphosate residues may have lingering effects on plant metabolic pathways, with potential consequences for plant physiology and performance (Fuchs et al. 2021). Specifically, glyphosate residues have been reported to reduce the germination, growth, and reproduction of crop plants (Helander et al. 2019; Muola et al. 2021), as well as weed biomass (Helander et al. 2018). However, the opposite result is also possible; at low doses, glyphosate may actually stimulate plant growth (e.g., Velini et al. 2008; Claassens et al. 2019). For example, faba beans exposed to glyphosate residues in the field were taller and had larger biomass than untreated control plants (Helander et al. 2019). Such inconsistency in the effects of glyphosate residues on plants may arise as a result of differences among plant species and in soil nutrient status, particularly with respect to phosphorus concentration. Phosphorus and glyphosate compete for the same binding sites in soil particles; in certain environments, phosphorus may outcompete glyphosate (e.g., Helander et al. 2012), thus increasing plants' exposure to glyphosate residues. Whether glyphosate has a positive or negative effect depends on the bioavailable concentration of glyphosate and the plant species. Moreover, the outcome of this competition, and thus the consequences for plants, are determined by abiotic environmental conditions, such as soil chemistry and weather conditions (Hébert et al. 2019 and references therein). Even with a single species, plants can demonstrate among-population differences in tolerance to glyphosate. As an example, in two annual weeds, Bromus diandrus and Lolium rigidum, ten examined populations of both species with no previous history of exposure to glyphosate showed varying dose responses to this herbicide (Barroso et al. 2010).

While previous studies have examined the effects of soil glyphosate residues independently on the various aspects of plant microbiota (e.g., KuklinskySobral et al. 2005; Kepler et al. 2020) or plant performance (e.g., Helander et al. 2019; Soares et al. 2019), few studies have considered these two factors simultaneously to explicitly discover the mechanistic links between them (but see Helander et al. 2018; Claassens et al. 2019). Here, we explore the effects of glyphosate residues on the endophytic microbiota and performance of the short-lived perennial weed Lupinus polyphyllus, using seed material from six introduced populations located on a latitudinal gradient in Finland. None of these populations has been exposed to glyphosate at least during the past ten years. The negative effects of $L$. polyphyllus on vascular plant diversity (Valtonen et al. 2006; Ramula and Pihlaja 2012) and arthropod abundance (Valtonen 
et al. 2006; Ramula and Sorvari 2017) make this species an unwanted invader. Regular mowing is used to gradually reduce population size, whereas herbicides (glyphosate-based or non-glyphosate-based) are required for more rapid eradication (Fremstad 2010). While L. polyphyllus is a target species, it also has properties that make it ideal for exploring the effects of glyphosate residues on plant-microbe interactions. As a legume, this species forms symbioses with nitrogen-fixing bacteria that can be particularly sensitive to glyphosate residues in soils in terms of growth and nodulation (dos Santos et al. 2005). Therefore, potential changes in plant-microbe interactions may reduce plant performance. We specifically addressed the following three questions: 1) Do glyphosate residues in soils reduce plant microbial (bacterial and fungal) richness and alter the composition of plant microbial communities? 2) Do glyphosate residues alter plant performance (height, retrogression probability, dry biomass, root:shoot ratio, nodule number, and nodule viability)? If so, what is the effect of soil phosphorus level on this relationship? 3) Do naïve weed populations differ in tolerance to glyphosate residues? Due to reductions in soil microbial richness after glyphosate application (Herath et al. 2017), we predicted that glyphosate residues in soils would reduce the richness of plant endophytic microbiota across tissue types, with concomitant alterations in microbial community composition. As a consequence, we hypothesised that glyphosate would reduce plant performance, particularly when the availability of phosphorus was abundant. Alternatively, glyphosate residues might increase plant performance in phosphorus-fertilised soils by enhancing the availability of phosphates for plants (Helander et al. 2019). As the six study populations represent a latitudinal gradient of about $440 \mathrm{~km}$ and show genetic differences based on 13 microsatellite loci ( $\mathrm{Li}$ et al. 2016), we expected to observe among-population differences in tolerance to glyphosate-treated soils.

\section{Methods}

Study species and populations

Lupinus polyphyllus (Lindl., garden lupin) is a perennial herb, $50-100 \mathrm{~cm}$ high, that is native to North
America and invasive in Europe, southern Australia, New Zealand, and Chile (Fremstad 2010). Due to its showy inflorescences and rhizomatous, soil-stabilising root system, the species has been used in horticulture and landscaping in its introduced range, where it currently inhabits road verges, wastelands, and forest understories (Fremstad 2010). An individual plant is able to produce hundreds of ballistically-dispersed seeds (Ramula 2014), which may remain viable in the soil for decades (Fremstad 2010).

In July 2018, we collected seeds from six populations of $L$. polyphyllus along a latitudinal gradient in Finland. In each population, seeds were collected from several haphazardly chosen plants that were at least two metres apart, and were stored in paper bags at room temperature.

Experiment 1: effects of glyphosate residues on plant microbiota and performance

At the beginning of May 2019, we chose 120 fully developed seeds from each population for a commongarden experiment. To remove epiphytic microbes, we surface-sterilised the seeds in $0.5 \%$ commercial bleach (sodium hypochlorite) solution for $15 \mathrm{~min}$ and rinsed them three times with deionised water. We hand-scarified seeds with a scalpel and sowed them individually into plastic trays $(16 \times 16$ pots of $2 \times 2 \mathrm{~cm}$ each) that were filled with a sterilised potting mix for garden plants (Kekkilä karkea ruukutusseos, autoclaved at $120{ }^{\circ} \mathrm{C}, 1 \mathrm{bar}, 20 \mathrm{~min}$ ). The germinated seedlings were grown in an unheated greenhouse (about $+23{ }^{\circ} \mathrm{C}$ day, $+12{ }^{\circ} \mathrm{C}$ night) for three weeks.

For the common-garden experiment, we utilised a long-term experimental setup involving the annual application of herbicides at the Ruissalo Botanical Garden $\left(60.4333^{\circ} \mathrm{N}, 22.1733^{\circ} \mathrm{E}\right)$ of the University of Turku, Finland. The mean annual temperature and precipitation in the area in 2019 were $7.4^{\circ} \mathrm{C}$ and $741 \mathrm{~mm}$, respectively (http://www.fmi.fi/en). The experimental field was established in 2013 by mixing sand $\left(12 \mathrm{~m}^{3}\right)$ and peat $\left(12 \mathrm{~m}^{3}\right)$ with existing clay soil ( $\mathrm{pH} \mathrm{7.1)} \mathrm{before} \mathrm{tilling} \mathrm{at} \mathrm{a} \mathrm{depth} \mathrm{of} 15 \mathrm{~cm}$. As a consequence, the top soil layer consisted of about $88 \%$ clay, $6 \%$ sand and $6 \%$ peat. The field was fenced with a metal net to keep out mammalian herbivores. The field contains 22 plots of $23 \times 1.5 \mathrm{~m}$ each that are $1.5 \mathrm{~m}$ apart. Since May 2014, the plots have been 
tilled with a rotary tiller twice per year (May and October) to a depth of $5 \mathrm{~cm}$, and sprayed with $5 \mathrm{~L}$ of either tap water (control plots) or tap water mixed with Roundup Gold (glyphosate concentration $450 \mathrm{~g}$ $\mathrm{L}^{-1}$, equivalent to the recommended maximum dose of $3 \mathrm{~kg} \mathrm{ha}^{-1}$ ), using a hand-operated pressure tank (see Helander et al. 2019 for details). Since spring 2018, half of each plot has been fertilised annually with phosphorus (Yara Ferticare ${ }^{\mathrm{TM}} \mathrm{P}-\mathrm{K}, 45 \mathrm{~kg} / \mathrm{ha}$ ) to create phosphorus-fertilised and ambient (non-fertilised) subplots. Crop plants (faba bean, turnip rape, oat, potato) have been cultivated in the plots since 2016.

In early June, 21 days after the last application of Roundup, we planted 12 seedlings (two seedlings per population, spaced about $15 \mathrm{~cm}$ apart) in each phosphorus-fertilised and ambient subplot, resulting in 24 plants in each control or glyphosate-treated plot; 528 plants in total. We measured plant height four days after planting to the nearest $0.5 \mathrm{~cm}$ and replaced 14 dead individuals with new seedlings. The plants were watered when necessary. To minimise interspecific plant competition, all of the plots were hand-weeded during the growing season, and about $5 \mathrm{~cm}$ of hemp bedding was added to the plots at the end of June. In late June and early August (23 and 59 days after planting, respectively), we recorded survival, the number of leaves, and the length of the longest leaf as a proxy for height for each individual plant. In August, we also recorded the number of flowering shoots, but did not use this variable for analysis due to the small number of flowering plants $(n=10$ and 9 plants in the glyphosate-treated and control plots, respectively, out of 528 plants). After the final measurements were taken in August, we harvested the plants to measure biomass and nodules; the latter was used as a proxy for colonisation by mutualists. We washed the roots and recorded the number and activity of nodules from one individual per subplot in each plot $(n=44$ plants in total representing the six study populations, with half of the samples coming from the P-fertilised subplots). We assessed nodule activity visually based on five dissected nodules per plant. Red nodules were considered active nitrogen-fixers, while white nodules were considered inactive or dead (Pommeresche and Hansen 2017). We separated shoot and root biomass and dried them at $+65^{\circ} \mathrm{C}$ for $48 \mathrm{~h}$ before weighing.

To analyse soil glyphosate concentrations, we collected samples from glyphosate- treated and control plots in mid-August 2019. The soil samples were sent to the certified laboratory, Groen Agro (https://agroc ontrol.nl/en/) for quantification of glyphosate and its main degradation product, aminomethylphosphonic acid (AMPA). The extraction was performed with a mixture of water and acidified methanol, and the analyses were conducted using a liquid chromatographytandem mass spectrometry (LC-MS/MS). The separation was performed with a mix mode column using a gradient based on mixture of water and acetonitrile.

\section{Sampling plant endophytic microbiota}

To characterise plant endophytic microbial communities, we destructively sampled two plants in each plot (one from the P-fertilised and non-fertilised subplot) in late July $(n=44$ plants equally distributed among the six study populations), leaving 484 plants in the experiment. From each plant, we clipped 2-3 healthy leaflets and nodule-containing pieces of roots using sterilised scissors. The samples were placed in plastic bags, stored on ice, and transported to the laboratory. We processed the three sample types (leaves, roots, nodules) in a laminar air-flow hood to minimise contamination. Approximately $100 \mathrm{mg}$ of each sample were washed in $70 \%$ ethanol for 1 min followed by $3 \%$ sodium hypochlorite solution for $3 \mathrm{~min}$. The samples were then rinsed three times with sterile deionised water for 1 min each and dried thoroughly before being transferred to $2-\mathrm{ml}$ microcentrifuge tubes and stored at $-80{ }^{\circ} \mathrm{C}$ until further processing. We prepared a negative control by plating $100 \mu$ of the third wash on an R2A plate and monitored it at room temperature for any microbial growth. Molecular methods for plant endophytic microbiota, including DNA extraction and bioinformatics are described in detail in Supplementary Information.

Experiment 2: effects of glyphosate-exposed soil microbiota on plant performance based on soil inoculation

To isolate the effects of glyphosate-exposed soil microbiota (if any) on plant performance, we conducted another common-garden experiment in which we explicitly manipulated soil microbiota. The seed sowing procedure was similar to that of 
Experiment 1, except that it took place about two weeks later. Scarified seeds (50 seeds from each of the six populations) were placed on a moist paper towel in foil containers, covered with plastic film, and left at room temperature $\left(+22{ }^{\circ} \mathrm{C}\right)$ for four days. The seedlings that emerged were planted in plastic trays of $30 \times 60 \mathrm{~cm}$ that were filled with sterilised potting mix and were grown in an unheated greenhouse for about a week, as described in Experiment 1. They were then subjected to one of two inoculation treatments in the common garden.

To ensure homogeneous growth conditions, we used a nutrient-poor, sterilised growth substrate (autoclaved at $+120{ }^{\circ} \mathrm{C}$ for $20 \mathrm{~min}$ ) consisting of $50 \%$ commercial sand (Kekkilä) and $50 \%$ potting mix (Kekkilä karkea ruukutusseos). The sterilised substrate was stored in black plastic bags outdoors until all substrate had been prepared $(<2$ weeks). For the two soil inoculation treatments, we collected $10 \mathrm{~L}$ soil, at a depth of $10 \mathrm{~cm}$, from the glyphosatetreated and untreated control plots from Experiment 1. The soil samples were obtained in equal measure from the P-fertilised and ambient subplots, and were mixed for the inoculation treatments. The soil collection took place at the end of May, a day after the end of the safety period recommended for Roundup application.

In the beginning of June, we allocated the seedlings into glyphosate and control inoculation treatments $(n=96)$, respectively, and planted them individually into plastic pots of $1 \mathrm{~L}$ filled with the sterilised substrate. To inoculate the pots, we added $0.5 \mathrm{dl}$ non-sterilised soil from either the glyphosatetreated or control plots to the surface of each pot (corresponding to about $4.8 \%$ of the volume; Howard et al. 2017). The pots were buried in sandy soil (about $20 \mathrm{~cm}$ apart) in 8 rows, separated by a $0.7-\mathrm{m}$ corridor. The sand field was fenced with a metal net to exclude mammalian herbivores. The field and pots were weeded twice during the growing season to avoid weed proliferation and were watered when necessary. The protocol and measurements taken from the individual plants were otherwise identical to those in Experiment 1, except that we did not sample plant microbiota. In addition, we recorded the number of nodules from all plants after harvest, and examined nodule activity from 12 randomly chosen plants per treatment ( 5 dissected nodules per plant).
Statistical analyses

\section{Plant endophytic microbiota}

To examine whether glyphosate residues affected the richness of plant endophytic microbiota, we conducted a linear mixed model (LMM, lme4::lmer; Bates et al. 2015) analysis separately for the bacterial and fungal data in R software (R3.5.3; R Development Core Team 2019). The number of OTUs based on subsampled data was used as a response variable; glyphosate treatment (glyphosate, control), phosphorus (fertilised, ambient), plant tissue type (nodule, root, leaf), and all possible interactions were fixed categorical explanatory variables; and subplot nested within plot was included as a random factor. After discarding the two samples with the fewest reads per tissue type, we subsampled the data to the same threshold value of reads (374 for bacteria and 627 for fungi). For fungi, the number of OTUs was logarithmically transformed to ensure the normality of residuals. In addition to plant microbial richness, we investigated differences in plant microbial community composition with permutational multivariate analyses of variance (PERMANOVA, implemented in vegan::adonis; Oksanen et al. 2020) separately for bacteria and fungi. PERMANOVA was conducted, with 999 permutations, based on Bray-Curtis dissimilarities calculated from the relative abundances of OTUs per sample $(n=516$ for bacteria and 433 for fungi), and contained the same fixed explanatory variables as the LMMs described above. To highlight OTUs that contributed to major differences in the composition of plant bacterial communities, we conducted indicator analyses with glyphosate treatment as a grouping variable for the relative abundances of OTUs (multipatt::indicspecies with func=r.g; De Caceres and Legendre 2009).

\section{Plant performance}

To analyse the effects of glyphosate-treated soils on plant performance in the two common-garden experiments, we used linear (LMM) or generalised linear (GLMM) mixed models, with initial plant height at the beginning of the experiment as a covariate. Survival was not considered as nearly all plants survived in both experiments ( $96.2 \%$ and $99.0 \%$, respectively). 
For Experiment 1, we conducted an LMM for plant height with glyphosate treatment (glyphosate, control), phosphorus (fertilised, ambient), time (June, August), and all possible interactions as fixed categorical explanatory variables. Population and subplot nested within plot were included as random factors. To consider repeated measurements taken from the same plants, plant ID was also included as a random factor in the model. We analysed the effects of glyphosate and phosphorus treatments on the probability of retrogression to smaller size (i.e. shrinkage in size between the two consecutive measurements) with a binomial, logit-link GLMM (lme4::glmer) with the same model structure as described above. In other words, retrogression occurred if an individual plant was shorter at time $t+1$ than at time $t$. The effects of glyphosate treatment, phosphorus, and their interaction on total biomass, root:shoot ratio, and the number of nodules were analysed with an LMM, while a binomial, logit-link GLMM was used to examine the effects on nodule activity (active, inactive). Population and subplot nested within plot were used as random factors for analyses of biomass and root:shoot ratio because multiple measurements were taken from the same subplot, while population and plot were used as random factors for analyses of nodules, for which only a single plant was sampled per subplot.

For Experiment 2, we analysed the effect of glyphosate-exposed soil microbiota on plant height with an LMM and determined the effect on retrogression probability with a binomial, logit-link GLMM, using soil inoculum (glyphosate, control), time (June, August), and their interaction as fixed categorical explanatory variables. Row, population, and plant ID were included as random factors to consider repeated measurements from the same individuals. Moreover, an LMM was conducted for total biomass, root:shoot ratio, and the number of nodules, with soil inoculum as a fixed factor and population and row as random factors. Finally, we analysed nodule activity with a binomial, logit-link GLMM using soil inoculum as a fixed explanatory variable and population as a random factor.

For all models, we examined whether the six populations responded differentially to the glyphosate or soil inoculation treatments by fitting different slopes across populations and by comparing model AICs. We verified model assumptions visually from residual plots for the linear models, and transformed the response variable when necessary (see Tables 3 and 4 for details). For the GLMMs, we checked for potential overdispersion in the residuals and found none (dispersion factor being $<0.98$ ). The significance of the fixed variables was evaluated with an $F$ test based on the Kenward-Roger method for LMMs (lmerTest::anova; Kuznetsova et al. 2017) and with a Wald chi-square test for GLMMs (car::Anova; Fox and Weisberg 2019). For significant interactions (Table 4), differences in mean values between treatments were assessed with contrasts (emmeans::Ismeans; Lenth 2020).

\section{Results}

Experiment 1: effects of glyphosate residues on plant microbiota and performance

The analysis confirmed that glyphosate-treated soils contained $0.42 \pm 0.36 \mathrm{mg} / \mathrm{kg}$ of glyphosate and $1.85 \pm 0.24 \mathrm{mg} / \mathrm{kg}$ of AMPA, while negative control plots did not contain detectable residues of glyphosate or AMPA.

\section{Plant endophytic microbiota}

Our analysis of plant bacterial communities yielded a total of 383803 sequence reads; these were classified into 516 OTUs, representing 13 bacterial phyla and 1 archaeal phylum. Of these, more than 150 bacterial OTUs were assigned to one of two major families, with $18.7 \%$ OTUs belonging to Bradyrhizobiaceae (abundant particularly in nodule tissues) and $14.1 \%$ OTUs belonging to Comamonadaceae. The analysis of plant fungal communities recovered a total of 203098 high-quality reads which were categorised into 433 OTUs. These OTUs were assigned to eight phyla but were predominantly Ascomycota (64.0\%) and Basidiomycota (23.8\%). Overall, 106 fungal families were represented, but the majority of them consisted of a few OTUs only.

The bacterial and fungal richness of plant tissues were similar between glyphosate-treated and control soils, but were modified by soil phosphorus level (Table 1). Plant bacterial richness was higher in phosphorus-fertilised soils than in those with the ambient level of phosphorus (mean $\pm \mathrm{SE}=51.2 \pm 2.3$ 
Table 1 Results of mixed models analysing the microbial richness associated with the perennial herb Lupinus polyphyllus in Experiment 1

Richness was based on the number of operational taxonomic units (OTUs). Plot was included as a random factor. $\mathrm{df}$ and ddf denote the degrees of freedom in the numerator and in the denominator, respectively, and $p$-values $<0.05$ are in bold

\begin{tabular}{llrrr}
\hline Response variable & Explanatory variable & F & $d f / d d f$ & $p$ \\
\hline Bacterial richness & Glyphosate (yes, no) & 0.29 & $1 / 19$ & 0.599 \\
& Phosphorus (ambient, fertilised) & $\mathbf{1 0 . 5 4}$ & $\mathbf{1 / 2 3}$ & $\mathbf{0 . 0 0 4}$ \\
& Tissue (leaf, root, nodule) & 2.06 & $2 / 69$ & 0.136 \\
& Glyphosate $\times$ Phosphorus & 0.42 & $1 / 19$ & 0.523 \\
& Glyphosate $\times$ Tissue & 0.01 & $2 / 69$ & 0.993 \\
& Phosphorus $\times$ Tissue & 0.13 & $2 / 69$ & 0.881 \\
& Glyphosate $\times$ Phosphorus $\times$ Tissue & 0.19 & $2 / 69$ & 0.827 \\
& Glyphosate & 0.26 & $1 / 19$ & 0.613 \\
& Phosphorus & $\mathbf{6 . 1 6}$ & $\mathbf{1 / 2 3}$ & $\mathbf{0 . 0 2 1}$ \\
& Tissue & $\mathbf{5 . 9 6}$ & $\mathbf{2 / 6 9}$ & $\mathbf{0 . 0 0 4}$ \\
& Glyphosate $\times$ Phosphorus & 0.89 & $1 / 19$ & 0.357 \\
& Glyphosate $\times$ Tissue & 0.06 & $2 / 69$ & 0.942 \\
& Phosphorus $\times$ Tissue & 0.71 & $2 / 69$ & 0.495 \\
& Glyphosate $\times$ Phosphorus $\times$ Tissue & 2.06 & $2 / 69$ & 0.135 \\
\hline
\end{tabular}

and $40.9 \pm 2.2$ ), while the opposite was true for plant fungal richness (mean $\pm \mathrm{SE}=5.8 \pm 0.9$ and $8.5 \pm 0.9$; Table 1). Fungal richness also differed between plant tissue types (Table 1), being lower for nodules (mean $\pm \mathrm{SE}=4.8 \pm 1.0)$ than for roots $(9.5 \pm 1.0)$ and leaves $(7.2 \pm 1.0)$.

In plant tissues, the community composition of bacteria differed between glyphosate-treated and control soils (Table 2). At the phylum level, plant endophytic bacterial communities from both soil types were highly dominated by Proteobacteria (about $96 \%$ in both cases). At the family level, Bradyrhizobiaceae was the most abundant family for plants grown in glyphosate-treated and control soils followed by Comamonadaceae (Fig. 1a). At the finer (OTU) level, however, differences became apparent. A more-detailed indicator analysis revealed that 17 bacterial OTUs, mainly representing family Bradyrhizobiaceae, were associated with the plant bacterial communities for glyphosate-treated soils, while 25 bacterial OTUs, representing diverse families, particularly families in Comamonadaceae (order Burkholderiales), were associated with the plant bacterial communities in control soils (Supplementary Fig. 1). In contrast to bacteria, the community composition of fungi did not differ between plants grown
Table 2 Results of PERMANOVAs for the microbial community composition associated with the perennial herb Lupinus polyphyllus in Experiment 1

Microbial communities were based on operational taxonomic units (OTUs). df and ddf denote the degrees of freedom in the numerator and in the denominator, respectively, and $p$-values $<0.05$ are in bold

\begin{tabular}{llrrr}
\hline Response variable & Explanatory variable & F & $d f / d d f$ & $p$ \\
\hline Bacterial composition & Glyphosate (yes, no) & $\mathbf{2 . 9 6}$ & $\mathbf{1 / 1 1 9}$ & $\mathbf{0 . 0 1 8}$ \\
& Phosphorus (ambient, fertilised) & $\mathbf{4 . 8 9}$ & $\mathbf{1 / 1 1 9}$ & $\mathbf{0 . 0 0 2}$ \\
& Tissue (leaf, root, nodule) & $\mathbf{1 8 . 4 4}$ & $\mathbf{2 / 1 1 9}$ & $\mathbf{0 . 0 0 1}$ \\
& Glyphosate $\times$ Phosphorus & 0.46 & $1 / 119$ & 0.850 \\
& Glyphosate $\times$ Tissue & 1.03 & $2 / 119$ & 0.396 \\
& Phosphorus $\times$ Tissue & 1.76 & $2 / 119$ & 0.078 \\
Fungal composition & Glyphosate $\times$ Phosphorus $\times$ Tissue & 1.07 & $2 / 119$ & 0.361 \\
& Glyphosate $($ yes, no) & 1.13 & $1 / 119$ & 0.318 \\
& Phosphorus (ambient, fertilised) & $\mathbf{1 6 . 4 9}$ & $\mathbf{1 / 1 1 9}$ & $\mathbf{0 . 0 0 1}$ \\
& Tissue (leaf, root, nodule) & $\mathbf{1 6 . 6 6}$ & $\mathbf{2 / 1 1 9}$ & $\mathbf{0 . 0 0 1}$ \\
& Glyphosate $\times$ Phosphorus & 1.26 & $1 / 119$ & 0.235 \\
& Glyphosate $\times$ Tissue & 0.91 & $2 / 119$ & 0.487 \\
& Phosphorus $\times$ Tissue & $\mathbf{5 . 1 1}$ & $\mathbf{2 / 1 1 9}$ & $\mathbf{0 . 0 0 1}$ \\
& Glyphosate $\times$ Phosphorus $\times$ Tissue & 1.33 & $2 / 119$ & 0.172 \\
\hline
\end{tabular}


Fig. 1 Bacterial $\mathbf{a}, \mathbf{b}$ and fungal c, $\mathbf{d}$ community compositions at the family or phylym level across tissue types (leaf, root, nodule) for the perennial Lupinus polyphyllus grown in different soil treatments. Only the most abundant families or phyla are shown
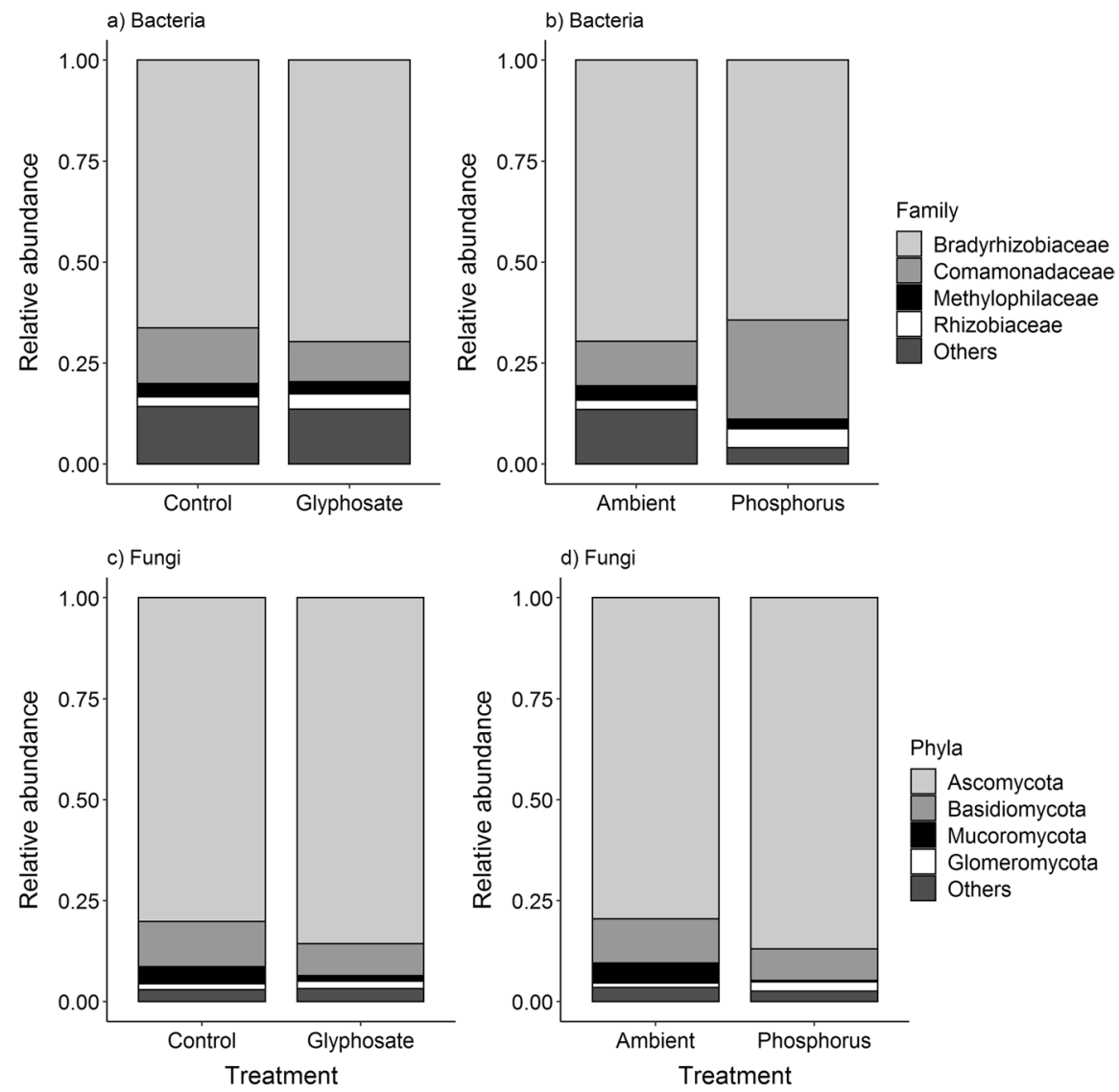

in glyphosate-treated and control soils (Table 2). In both cases, the four most abundant fungal phyla were Ascomycota, Basidiomycota, Mucoromycota, and Glomeromycota (Fig. 1b).

Phosphorus fertilisation altered the community composition of both endophytic bacteria and fungi compared to ambient, non-fertilised soil (Table 2). For bacteria, members in family Comamonadaceae were more abundant in plants grown in P-fertilised soil than in those grown in ambient soil (Fig. 1c). For fungi, Mucoromycota phylum was particularly rare in plants grown in P-fertilised soil (Fig. 1d).

\section{Plant performance}

Glyphosate and phosphorus treatments, either independently or via interactions, had no effect on any of the six plant traits considered (Table 3). As expected, plants were taller and less likely to shrink in size in late summer than in early summer (Table 3; height mean $\pm \mathrm{SD}=8.8 \pm 2.1 \mathrm{~cm}$ in June and $20.2 \pm 8.9 \mathrm{~cm}$ in August, and retrogression frequency $26.4 \pm 41.1 \%$ in June and $10.8 \pm 31.1 \%$ in August). Populationspecific slopes were not supported in any of the cases (model AICs were either equal or larger with different slopes than with the common slope, $\Delta \mathrm{AIC}>2$ ), suggesting similar responses among populations.

Experiment 2: effects of glyphosate-exposed soil microbiota on plant performance based on soil inoculation

Soil inoculation treatment had no effect on the six plant traits considered, but did interact with time to affect the probability of retrogression (Table 4). In August, the probability of retrogression was higher for plants grown in sterilised substrate inoculated with glyphosate-treated soil than for plants inoculated with control soil. In June, instead, soil inoculation treatment had no effect on the probability of 
Table 3 Results of mixed models analysing the performance of the perennial herb Lupinus polyphyllus in Experiment 1

\begin{tabular}{|c|c|c|c|c|}
\hline Response variable & Explanatory variable & $\mathrm{F} / \chi^{2}$ & $d f / d d f$ & $p$ \\
\hline \multirow[t]{4}{*}{ Total biomass (log) } & Glyphosate (yes, no) & 0.08 & $1 / 20$ & 0.779 \\
\hline & Phosphorus (ambient, fertilised) & 0.22 & $1 / 20$ & 0.642 \\
\hline & Initial height & 0.50 & $1 / 424$ & 0.479 \\
\hline & Glyphosate $\times$ Phosphorus & 1.72 & $1 / 20$ & 0.205 \\
\hline \multirow[t]{4}{*}{ Root:shoot-ratio (log) } & Glyphosate & 0.32 & $1 / 20$ & 0.572 \\
\hline & Phosphorus & 0.00 & $1 / 20$ & 0.949 \\
\hline & Initial height & 0.05 & $1 / 389$ & 0.822 \\
\hline & Glyphosate $\times$ Phosphorus & 1.33 & $1 / 20$ & 0.249 \\
\hline \multirow[t]{8}{*}{ Height (sqrt) } & Glyphosate & 0.05 & $1 / 20$ & 0.819 \\
\hline & Phosphorus & 0.79 & $1 / 20$ & 0.385 \\
\hline & Time (June, August) & 1073.49 & $1 / 975$ & $<0.001$ \\
\hline & Initial height & 49.62 & $1 / 916$ & $<0.001$ \\
\hline & Glyphosate $\times$ Phosphorus & 0.04 & $1 / 20$ & 0.854 \\
\hline & Glyphosate $\times$ Time & 0.70 & $1 / 975$ & 0.369 \\
\hline & Phosphorus $\times$ Time & 3.10 & $1 / 975$ & 0.078 \\
\hline & $\mathrm{G} \times \mathrm{P} \times$ Time & 1.78 & $1 / 975$ & 0.182 \\
\hline \multirow[t]{8}{*}{ Retrogression prob } & Glyphosate & 0.00 & $1 /$ na & 0.972 \\
\hline & Phosphorus & 1.23 & $1 /$ na & 0.268 \\
\hline & Time (June, August) & 43.63 & $1 /$ na & $<0.001$ \\
\hline & Initial height & 33.35 & $1 /$ na & $<0.001$ \\
\hline & Glyphosate $\times$ Phosphorus & 0.01 & $1 /$ na & 0.937 \\
\hline & Glyphosate $\times$ Time & 0.08 & $1 /$ na & 0.779 \\
\hline & Phosphorus $\times$ Time & 1.51 & $1 /$ na & 0.219 \\
\hline & $\mathrm{G} \times \mathrm{P} \times$ Time & 2.17 & $1 /$ na & 0.141 \\
\hline \multirow[t]{4}{*}{ No. nodules $(\log (\mathrm{x}+1))$} & Glyphosate & 0.31 & $1 / 19$ & 0.577 \\
\hline & Phosphorus & 0.02 & $1 / 16$ & 0.892 \\
\hline & Initial height & 0.05 & $1 / 30$ & 0.829 \\
\hline & Glyphosate $\times$ Phosphorus & 0.65 & $1 / 16$ & 0.419 \\
\hline \multirow[t]{4}{*}{ Nodule activity } & Glyphosate & 0.45 & $1 /$ na & 0.504 \\
\hline & Phosphorus & 2.84 & $1 / \mathrm{na}$ & 0.092 \\
\hline & Initial height & 0.03 & $1 /$ na & 0.876 \\
\hline & Glyphosate $\times$ Phosphorus & 0.00 & $1 /$ na & 0.955 \\
\hline
\end{tabular}

Population and plot (or population and subplot nested within plot) were used as random factors in all models. Plant ID was used as a random factor for height and retrogression in order to consider repeated measurements. df and ddf denote the degrees of freedom in the numerator and denominator (when applicable), respectively. $P$-values $<0.05$ are in bold, na $=$ not applicable for GLMMs consequently, plant microbiota (Fuchs et al. 2021). As predicted, we observed glyphosate-induced shifts in the endophytic microbiota of the perennial nitrogen-fixing weed $L$. polyphyllus. We discovered that OTUs belonging to Bradyrhizobiaceae were abundant in plants grown in both glyphosate-treated and control soils, and particularly so for the former soil type. Our observation of a high relative abundance of Bradyrhizobiaceae, which includes many nitrogenfixing bacteria, in the plant bacterial communities in glyphosate-treated soils seems inconsistent with previous findings that facultative host-associated bacteria are more sensitive to glyphosate than

microbial communities (Angelini et al. 2013) and, 
Table 4 Results of mixed models analysing the performance of the perennial herb Lupinus polyphyllus in Experiment 2

Row and population were used as random factors when appropriate; plant ID was used as a random factor for height and retrogression in order to consider repeated measurements. df and ddf denote the degrees of freedom in the numerator and in the denominator (when applicable), respectively. $P$-values $<0.05$ are in bold, na $=$ not applicable for GLMMs

\begin{tabular}{|c|c|c|c|c|}
\hline Response variable & Explanatory variable & $\mathrm{F} / \chi^{2}$ & $d f / d d f$ & $p$ \\
\hline \multirow[t]{2}{*}{ Total biomass (sqrt) } & $\begin{array}{l}\text { Soil inoculum (glyphosate, } \\
\text { control) }\end{array}$ & 1.45 & $1 / 163$ & 0.230 \\
\hline & Initial height & 5.98 & $1 / 175$ & 0.016 \\
\hline \multirow[t]{2}{*}{ Root:shoot-ratio (log) } & Soil inoculum & 1.52 & $1 / 180$ & 0.219 \\
\hline & Initial height & 8.15 & $1 / 182$ & 0.005 \\
\hline \multirow[t]{4}{*}{ Height (log) } & Soil inoculum & 0.06 & $1 / 175$ & 0.812 \\
\hline & Time (June, August) & 331.40 & $1 / 178$ & $<0.001$ \\
\hline & Initial height & 75.17 & $1 / 188$ & $<0.001$ \\
\hline & Soil inoculum $\times$ Time & 3.29 & $1 / 188$ & 0.070 \\
\hline \multirow[t]{4}{*}{ Retrogression prob } & Soil inoculum & 0.01 & $1 /$ na & 0.911 \\
\hline & Time (June, August) & 5.23 & $1 /$ na & 0.022 \\
\hline & Initial height & 2.29 & $1 /$ na & 0.131 \\
\hline & Soil inoculum $\times$ Time & 4.74 & $1 /$ na & 0.029 \\
\hline \multirow[t]{2}{*}{ No. nodules $(\log (\mathrm{x}+1))$} & Soil inoculum & 2.68 & $1 / 181$ & 0.102 \\
\hline & Initial height & 1.44 & $1 / 180$ & 0.231 \\
\hline \multirow[t]{2}{*}{ Nodule activity } & Soil inoculum & 1.04 & $1 /$ na & 0.308 \\
\hline & Initial height & 1.01 & $1 /$ na & 0.315 \\
\hline
\end{tabular}

free-living bacteria (Rainio et al. 2021), and that glyphosate can reduce the growth of Bradyrhizobium strains (e.g., de Maria et al. 2005; dos Santos et al. 2005). One possible explanation for our result is that plants grown in glyphosate-treated soils may have been more limited by nitrogen than plants grown in untreated control soils and, thus, harbour a higher abundance of nitrogen-fixing bacteria from family Bradyrhizobiaceae. With respect to fungi, even though previous studies have reported that

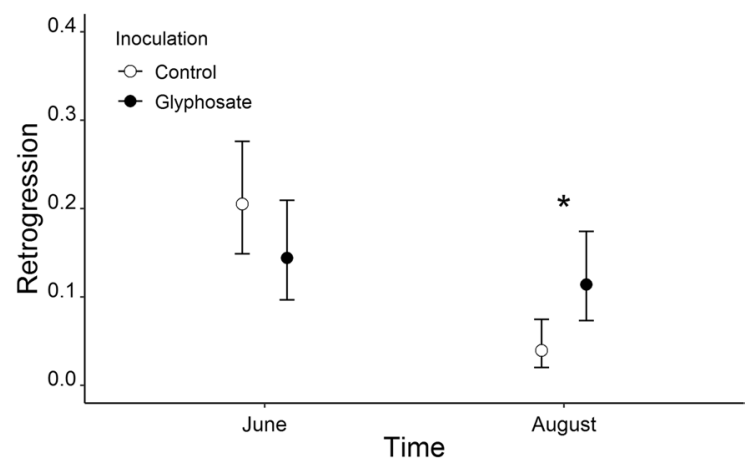

Fig. 2 The probability of retrogression to a smaller size in the perennial Lupinus polyphyllus (back-transformed least square mean $\pm \mathrm{SE}$ ) grown in sterilised substrates inoculated with either control or glyphosate-treated soils. An asterisk denotes a significant difference between the soil inoculation treatments $(p<0.05$, contrasts) at a given time glyphosate residues can reduce root colonisation by fungal symbionts (Helander et al. 2018; Claassens et al. 2019), we observed no shifts in plant fungal communities in glyphosate-treated soils. In the present study, the plant fungal communities were highly dominated by members in the largest phylum of fungi, Ascomycota, regardless of treatment. Furthermore, similar to Kepler et al. (2020), we found that glyphosate residues in soils had no effect on plant endophytic bacterial richness per se despite the fact that glyphosate treatment had been applied annually for six years. Taken together, these results highlight the necessity of more-detailed taxonomic studies to assess the consequences of glyphosate residues for plant microbiota.

Phosphorus competes with glyphosate for the same sorption sites in soil particles (Helander et al. 2012; Kanissery et al. 2019). As a consequence, phosphorus fertilisation may reduce glyphosate sorption (Vereecken 2005; Hébert et al. 2019) increasing its mobility and harmful effects on plants (Bott et al. 2011). Contrary to our prediction, however, glyphosate had no effect on plant microbiota or on plant performance at either of the phosphorus levels examined here. Soil phosphorus thus played a negligible role in mediating the effects of glyphosate on plant-microbe interactions and the performance of the study species. Unfortunately, we cannot assess 
whether this negligible effect was due to small differences in the phosphorus concentration between the two treatments because we did not explicitly determine soil phosphorus during the experiment. Regardless of the exact phosphorus concentrations of the two treatments, P-fertilisation did alter plant microbiota, as indicated by structural differences in both bacterial and fungal communities between plants grown in fertilised and non-fertilised soils. More specifically, P-fertilisation reduced the abundance of Mucoromycota, many of which are mycorrhizal fungi and root endophytes (Bonfante and Venice 2020).

Herbicide-induced shifts in plant microbiota, such as those detected in this study, could plausibly result in alterations in plant growth. Here, however, glyphosate treatments had only a negligible effect on plant height, biomass, and root:shoot allocation. Indeed, the only significant effect on plant performance we observed was that plants grown in sterilised substrate that had been inoculated with glyphosate-treated soil were more likely to shrink in size in late summer than plants that had been inoculated with control soil. This finding may indicate that glyphosate residues altered soil microbiota in such a way as to negatively affect plant growth and increase the probability of retrogression. In plants, size is generally a good measure of an individual's performance (Caswell 2001) and therefore, retrogression to a smaller size might be a sign of the poor resource status of an individual (Shefferson and Roach 2013). In the study species used here, smaller size is associated with lower survival, growth, flowering probability, and seed production (Ramula 2014). Given this size-dependence in plant traits, our finding suggests that soil nutrient status may play an important role in the chemical control of weeds, with glyphosate-based herbicides being a more effective method of control in nutrient-poor soils than in nutrient-rich soils.

Despite the increased probability of retrogression, the glyphosate treatments had no effect on nodulation in the present study. The negligible effect on nodulation may simply indicate that the growth of $L$. polyphyllus was not constrained by the availability of nitrogen-fixing bacteria in soils. The importance of nitrogen-fixing bacteria for legumes varies depending on soil nutrient status, with nitrogen-fixers being less beneficial in nitrogen-rich soils than in nitrogen-poor soils (Simms and Taylor 2002; Dean et al. 2014); therefore, plants may contain fewer nodules in soils with more nitrogen (Goergen et al. 2009; Dean et al. 2014). Indeed, the plants in Experiment 1 produced about four times fewer nodules than the plants in Experiment 2 (mean $\pm \mathrm{SD}=11.48 \pm 9.74$ and $39.44 \pm 23.03$, respectively) despite their larger size (biomass: $6.61 \mathrm{~g}$ and $3.83 \mathrm{~g}$, respectively), suggesting that growth conditions were particularly favourable in Experiment 1. Despite the lower numbers of nodules in Experiment 1, potential nitrogen-fixing bacteria from family Bradyrhizobiaceae were abundant in plant bacterial communities from both glyphosatetreated and control soils $(69.7 \%$ and $66.3 \%$, respectively), although the relative abundance of individual OTUs representing this family differed between the two soil types. Previous studies have revealed that L. polyphyllus can effectively nodulate with multiple commonly occurring strains of Bradyrhizobium spp. (Stepkowski et al. 2007; Ryan-Salter et al. 2014); in other words, the strain of the nitrogen-fixing partner is not of critical importance. However, because we considered the number of nodules only, we cannot rule out the possibility that the glyphosate treatments might have affected nodulation and plants' nitrogenfixing capacities through effects on nodule structure (de Maria et al. 2005) or nodule size, with larger nodules being more effective than smaller ones (e.g., Simms and Taylor 2002).

In the present study, plants originating from the six populations of L. polyphyllus responded similarly to the glyphosate treatments, suggesting that among-population differences in sensitivity to glyphosate residues were minimal. The similarity of their responses could be due to the low concentrations of glyphosate that were used here. Previous studies that have reported intraspecific variation in plant tolerance to glyphosate have usually examined direct responses to herbicide application based on dose-response bioassays (e.g., Barroso et al. 2010; Panozzo et al. 2020), in which plants are typically exposed to much higher concentrations of glyphosate than those used here. Overall, our results support the previous finding that plants may be less sensitive to glyphosate residues than their associated micro-organisms (Claassens et al. 2019). As the effects of glyphosate residues have been primarily examined for crop plants (e.g., Helander et al. 2019; Claassens et al. 2019; Soares et al. 2019), it remains to be confirmed whether short-lived weeds are generally more resistant to glyphosate residues than crop plants. 
To conclude, we found that glyphosate residues in soils altered the composition of the endophytic microbial communities associated with the study species, with changes being more pronounced for bacteria than for fungi. In particular, bacteria of the family Bradyrhizobiaceae dominated in plants grown in glyphosate-treated soils. Interestingly, despite these alterations in plant endophytic microbiota, glyphosate residues had only a minor effect on plant performance. Only one out of the six plant traits considered was partially affected by glyphosate treatments: plants grown on a nutrient-poor substrate and inoculated with glyphosate-exposed soil microbiota showed a higher probability of retrogression (i.e. shrinkage in size) in late summer than plants inoculated with the control soil. The present study demonstrates that glyphosate residues in northern soils are able to modify the composition of plant bacterial communities across tissue types (from roots and nodules to leaves). However, the effects of this herbicide on plant endophytic microbiota may have a minimal impact on the performance of invasive plants, particularly in nutrient-rich environments.

Acknowledgements We thank Suvi Hakulinen and other field assistants and postdocs for helping with the experiments. This work was supported by the Academy of Finland (\#285746 and \#331046 to SR, \#311077 to MH) and Turku Collegium of Science and Medicine (AK).

Authors' contributions The study was designed by Satu Ramula, Aino Kalske, Marjo Helander, and Kari Saikkonen. The field work was conducted by Satu Ramula and Aino Kalske, and the microbiota analysis was conducted by Suni Mathew and Riitta Nissinen. Data were analysed and the first draft of the manuscript was written by Satu Ramula, all authors commented on previous versions of the manuscript and approved the final manuscript.

Funding Open Access funding provided by University of Turku (UTU) including Turku University Central Hospital. This work was supported by the Academy of Finland (\#285746 and \#331046 to SR, \#311077 to MH) and Turku Collegium of Science and Medicine (AK).

Availability of data and material The datasets generated and analysed during the study are available from the Dryad Digital Repository https://doi.org/10.5061/dryad.nvx0k6dth.

Code availability Not applicable.

\section{Declarations}

Conflict of interest The authors declare no conflicts of interest.
Open Access This article is licensed under a Creative Commons Attribution 4.0 International License, which permits use, sharing, adaptation, distribution and reproduction in any medium or format, as long as you give appropriate credit to the original author(s) and the source, provide a link to the Creative Commons licence, and indicate if changes were made. The images or other third party material in this article are included in the article's Creative Commons licence, unless indicated otherwise in a credit line to the material. If material is not included in the article's Creative Commons licence and your intended use is not permitted by statutory regulation or exceeds the permitted use, you will need to obtain permission directly from the copyright holder. To view a copy of this licence, visit http://creativecommons.org/licenses/by/4.0/.

\section{References}

Angelini J, Silvina G, Taurian T, Ibanez F, Tonelli ML, Valetti L, Anzuay MS, Luduena L, Munoz V, Fabra A (2013) The effects of pesticides on bacterial nitrogen fixers in peanutgrowing area. Arch Microbiol 195:683-692

Barroso J, Loureiro I, Escorial MC, Chueca MC (2010) The response of Bromus diandrus and Lolium rigidum to dalapon and glyphosate I: baseline sensitivity. Weed Res 50:312-319

Bates D, Mächler M, Bolker BM, Walker SC (2015) Fitting linear mixed-effects models using lme4. J Stat Software 67:1-48

Baylis AD (2000) Why glyphosate is a global herbicide: strengths, weaknesses and prospects. Pest Manag Sci 56:299-308

Bonfante P, Venice F (2020) Mucoromycota: going to the roots of plant-interacting fungi. Fungal Biol Review 34:100-113

Bott S, Tesfamariam T, Kania A, Eman B, Aslan N, Römheld V, Neumann G (2011) Phytotoxicity of glyphosate soil residues re-mobilised by phosphate fertilization. Plant Soil 342:249-263

Caswell H (2001) Matrix population models: construction, analysis, and interpretation. Sunderland, Massachusetts

Claassens A, Rose MT, Van Zwieten L, Weng ZH, Rose TJ (2019) Soilborne glyphosate residue thresholds for wheat seedling metabolite profiles and fungal root endophyte colonization are lower than for biomass production in a sandy soil. Plant Soil 438:393-404

Compant S, Samad A, Faist H, Sessitsch A (2019) A review on the plant microbiome: ecology, functions, and emerging trends in microbial application. J Adv Res 19:29-37

De Caceres M, Legendre P (2009) Associations between species and groups of sites: indices and statistical inference. Ecology 90:3566-3574

de Maria N, de Felipe MR, Fernández-Pascual M (2005) Alterations induced by glyphosate on lupin photosynthetic apparatus and nodule ultrastructure and some oxygen diffusion related proteins. Plant Phys Biochemistry 43:985-996

Dean JM, Mescher MC, De Moraes CM (2014) Plant dependence on Rhizobia for nitrogen influences induced plant 
defenses and herbivore performance. Int $\mathrm{J}$ Mol Sci 15:1466-1480

dos Santos JB, Ferreira EA, Kasuyab MCM, da Silva AA, de Oliverira PS (2005) Tolerance of Bradyrhizobium strains to glyphosate formulations. Crop Prot 24:543-547

Duke SO, Powles SB (2008) Glyphosate: a once-in-a-century herbicide. Pest Manag Sci 64:319-325

Fox J, Weisberg S (2019) An R companion to applied regression, 3rd edn. Sage, Thousand Oaks

Fremstad E (2010) NOBANIS - Invasive Alien Species Fact Sheet - Lupinus polyphyllus. In: Online Database of the European Network on Invasive Alien Species NOBANIS. Available at: www.nobanis.org. Accessed 1 Apr 2020

Fuchs B, Saikkonen K, Helander M (2021) Glyphosate-modulated biosynthesis driving plant defense and species interactions. Trends Plant Sci 26:312-323. https://doi.org/10. 1016/j.tplants.2020.11.004

Goergen E, Chambers JC, Blank R (2009) Effects of water and nitrogen availability on nitrogen contribution by the legume, Lupinus argenteus Pursh. Appl Soil Ecol 42:200-208

Gómez-Gallego C, Raiio MJ, Collado MC, Mantziari A, Salminen S, Saikkonen K, Helander M (2020) Glyphosate-based herbicide affects the composition of microbes associated with Colorado potato beetle (Leptinotarsa decemlineata). FEMS Microbiol Lett 367:fnaa050

Helander M, Saloniemi I, Saikkonen K (2012) Glyphosate in northern ecosystems. Trends Plant Sci 17:569-574

Helander M, Saloniemi I, Omacini M, Druille M, Salminen J-P, Saikkonen K (2018) Glyphosate decreases mycorrhizal colonization and affects plant-soil feedback. Sci Total Env 642:285-291

Helander M, Pauna A, Saikkonen K, Saloniemi I (2019) Glyphosate residues in soil affect crop plant germination and growth. Sci Reports 9:19653

Herath HMLI, Moldrup P, de Jonge LW, Nicolaisen M, Norgaard T, Arthur E, Paradelo M (2017) Clay-to-carbon ratio controls the effect of herbicide application on soil bacterial richness and diversity in a loamy field. Water Air Soil Pollut 228:3

Hebért M-P, Fugere V, Gonzalez A (2019) The overlooked impact of rising glyphosate use on phosphorus loading in agricultural watersheds. Front Ecol Environ 17:48-56

Howard MM, Bell TH, Kao-Kniffin J (2017) Soil microbiome transfer method affects microbiome composition, including dominant microorganisms, in a novel environment. FEMS Microbiol Lett 364:fnx092

Kanissery R, Gairhe B, Kadyampakeni D, Batuman O, Alferez F (2019) Glyphosate: its environmental persistence and impact on crop health and nutrition. Plants 8:499

Kepler RM, Schmidt DJE, Yarwood SA, Cavigelli MA, Reddy KN, Duke SO, Bradley CA, Williams MM II, Buyer JS, Maul JE (2020) Soil microbial communities in diverse agroecosystems exposed to the herbicide glyphosate. Appl Env Microbiol 86:e01744-e1819

Kettenring KM, Reinhardt Adams C (2011) Lessons learned from invasive plant control experiments: a systematic review and meta-analysis. J Appl Ecol 48:970-979

Kuklinsky-Sobral J, Araújo WL, Mendes R, Pizzirani-Kleiner AA, Azevedo JL (2005) Isolation and characterization of endophytic bacteria from soybean (Glycine max) grown in soil treated with glyphosate herbicide. Plant Soil 273:91-99

Kuznetsova A, Brockhoff PB, Christensen RHB (2017) lmerTest package: tests in linear mixed effects models. J Stat Softw 82:1-26

Laitinen P, Rämö S, Siimes K (2009) Glyphosate and phosphorus leaching and residues in boreal sandy soil. Plant Soil 323:267-283

Leino L, Tall T, Helander M, Saloniemi I, Saikkonen K, Ruuskanen S, Puigbò P (2021) Classification of the glyphosate target enzyme (5-enolpyruvylshikimate-3-phosphate synthase) for assessing sensitivity of organisms to the herbicide. J Haz Mater 408:124556

Lenth R (2020) emmeans: estimated marginal means, aka leastsquares means. R package version 1.4.5. https://CRAN.Rproject.org/package $=$ emmeans

Li S-L, Vasemägi A, Ramula S (2016) Genetic variation and population structure of the garden escaper Lupinus polyphyllus in Finland. Plant Syst Evol 302:399-407

Muola A, Fuchs B, Laihonen M, Rainio K, Heikkonen L, Ruuskanen S, Saikkonen K, Helander M (2021) Risk in the circular food economy: glyphosate-based herbicide residues in manure fertilizers decrease crop yield. Sci Tot Env 750:141422

Oksanen J, Blanchet FG, Friendly M, Kindt R, Legendre P, McGlinn D, Minchin PR, O'Hara RB, Simpson GL, Solymos P, Stevens MHM, Szoecs E, Wagner H (2020) Vegan: community ecology package

Panozzo S, Collavo A, Sattin M (2020) Sensitivity analysis of Italian Lolium spp. glyphosate in agricultural environments. Plants 9:165

Pommeresche R, Hansen S (2017) Examining root nodule activity on legumes. Technical Note. Research Institut of Organic Agriculture (FiBL), CH-Frick and Norwegian Centre for Organic Agriculture (NORSØK), NO-Tingvoll

Rainio MJ, Ruuskanen S, Helander M, Saikkonen K, Saloniemi I, Puigbò P (2021) Adaptation of bacteria to glyphosate: a microevolutionary perspective of the enzyme 5-enolpyruvylshikimate-3-phosphate (EPSP) synthase. Env Microbiol Reports 13:309-316

Ramula S (2014) Linking vital rates to invasiveness of a perennial herb. Oecologia 174:1255-1264

Ramula S, Pihlaja K (2012) Plant communities and the reproductive success of native plants after the invasion of an ornamental herb. Biol Invasions 14:2079-2090

Ramula S, Sorvari J (2017) The invasive herb Lupinus polyphyllus attracts bumblebees but reduces total arthropod abundance. Arthropod-Plant Interactions 11:911-918

R Development Core Team (2019) R: a language and environment for statistical computing. Version 3.5.3. R Foundation for Statistical Computing, Vienna. https://www.R-project.org/

Ryan-Salter TP, Black AD, Andrews M, Moot DJ (2014) Identification and effectiveness of rhizobial strains that nodulate Lupinus polyphyllus. Proc New Zealand Grassland Assoc 76:61-66

Shefferson RP, Roach DA (2013) Longitudinal analysis in Plantago: Strength of selection and reverse age analysis reveal age-indeterminate senescence. J Ecol 101:577-584

Simms EL, Taylor DL (2002) Partner choice in nitrogen-fixation mutualisms of legumes and Rhizobia. Integr Comp Biol 42:369-380 
Soares C, Pereira R, Spormann S, Fidalgo F (2019) Is soil contamination by a glyphosate commercial formulation truly harmless to non-target plants? - Evaluation of oxidative damage and antioxidant responses in tomato. Environ Pollut 247:256-265

Stepkowski T, Hughes CE, Law IJ, Markiewicz L, Gurda D, Chlebicka A, Moulin L (2007) Diversification of lupine Bradyrhizobium strains: evidence from nodulation gene trees. Appl Environ Microbiol 73:3254-3264

Valtonen A, Jantunen J, Saarinen K (2006) Flora and lepidoptera fauna adversely affected by invasive Lupinus polyphyllus along road verges. Conserv Biol 133:389-396
Velini ED, Alves E, Godoy MC, Meschede DK, Souza RT, Duke SO (2008) Glyphosate applied at low doses can stimulate plant growth. Pest Manag Sci 64:489-496

Vereecken H (2005) Mobility and leaching of glyphosate: a review. Pest Manage Sci 61:1139-1151

Publisher's note Springer Nature remains neutral with regard to jurisdictional claims in published maps and institutional affiliations. 